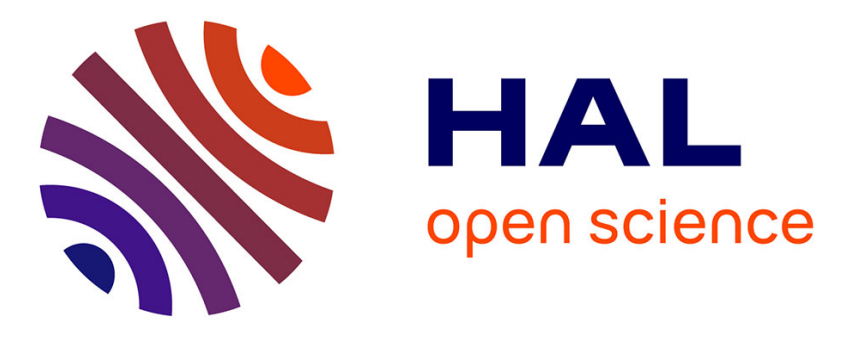

\title{
Three Apps for Shooting Sports: The Design, Development, and Deployment
}

Agnieszka Besz, Maciej Górnicki, Toni Heinonen, Tapani Kiikeri, Ilkka Ratamo, Mika Luimula, Taisto Suominen, Aki Koponen, Jouni Saarni, Tomi "bgt" Suovuo, et al.

\section{To cite this version:}

Agnieszka Besz, Maciej Górnicki, Toni Heinonen, Tapani Kiikeri, Ilkka Ratamo, et al.. Three Apps for Shooting Sports: The Design, Development, and Deployment. 14th International Conference on Entertainment Computing (ICEC), Sep 2015, Trondheim, Norway. pp.329-342, 10.1007/978-3-31924589-8_25. hal-01758418

\section{HAL Id: hal-01758418 https://hal.inria.fr/hal-01758418}

Submitted on 4 Apr 2018

HAL is a multi-disciplinary open access archive for the deposit and dissemination of scientific research documents, whether they are published or not. The documents may come from teaching and research institutions in France or abroad, or from public or private research centers.
L'archive ouverte pluridisciplinaire HAL, est destinée au dépôt et à la diffusion de documents scientifiques de niveau recherche, publiés ou non, émanant des établissements d'enseignement et de recherche français ou étrangers, des laboratoires publics ou privés.

\section{(c)(1)}

Distributed under a Creative Commons Attribution| 4.0 International License 


\title{
Three Apps for Shooting Sports: The Design, Development, and Deployment
}

\author{
Agnieszka Besz ${ }^{1}$, Maciej Górnicki ${ }^{1}$, Toni Heinonen ${ }^{1}$, Tapani Kiikeri ${ }^{2}$, Ilkka \\ Ratamo $^{2}$, Mika Luimula ${ }^{3}$, Taisto Suominen ${ }^{3}$, Aki Koponen ${ }^{4}$, Jouni Saarni ${ }^{4}$, \\ Tomi "bgt" Suovuo ${ }^{5}$, and Jouni Smed ${ }^{5}$ \\ 1 Turku Game Lab, Turku University of Applied Sciences and University of Turku \\ agnieszka.besz@utu.fi, maciej.gornicki@utu.fi, toni.heinonen@turkuamk.fi \\ 2 Rightspot Ltd., Salo, Finland \\ tapani.kiikeri@rightspot.fi, ilkka.ratamo@rightspot.fi \\ 3 Business, ICT and Life Sciences, Turku University of Applied Sciences \\ mika.luimula@turkuamk.fi, taisto.suominen@turkuamk.fi \\ 4 Turku School of Economics, University of Turku \\ aki.koponen@utu.fi, jouni.saarni@utu.fi \\ 5 Department of Information Technology, University of Turku \\ bgt@sci.fi, jouni.smed@utu.fi
}

\begin{abstract}
Video games rarely simulate shooting sports accurately. In this paper, we introduce three mobile applications that try to convey the essence of target shooting and biathlon to the players. We look at the applications from the perspectives of game design, implementation, and marketing. Our analysis provides a basis for developing games that take a real-world sport and help the player to appreciate the nuances of the sport, and maybe even to try it out in reality.
\end{abstract}

Keywords: mobile games, shooting sports, sport games, biathlon, game development, game design, mobile marketplaces

\section{Introduction}

Sport games (together with shooters) can be called one of the original video game genres, starting from Tennis for Two created by William Higinbotham in 1958 [6, pp. 37-40]. Although shooting has been an integral part of video games, games focusing on shooting sports have been less common. The earliest commercial example is the rifle-shaped light gun of Magnavox Odyssey from 1972, which could be used with cartridge \#10, "Shooting Gallery". Early sport games such as Summer Games [2], Hyper Sports [9] and International Sports Challenge [4] included skeet shooting in the events. Another typical shooting sport is biathlon, which is part of Winter Games [3], Winter Olympiad 88 [17], and Winter Olympics: Lillehammer '94 [19].

A typical feature of both the examples listed above and the modern-day video game shooting sports is that they are very simplified. They approach shooting from the point of view of a game and try make the sport as play-like as 
possible. This differs from the design philosophy we have engaged in our work. Our approach towards these applications is more from a simulation than game. We wish to engage the user in the experience of how it really is to compete in target shooting or in a biathlon competition. Hence our applications are more like the Microsoft Flight Simulator [16] or the Microsoft Train Simulator [10] than the games mentioned earlier.

In this paper, we will present three applications for shooting sports-Kurt Thune Training, Pete Patruuna, and Biathlon X5 - designed and developed by Turku Game Lab in co-operation with Rightspot Ltd. The plan of the paper is as follows: In Sect. 2, we describe our three applications and their intended use and underlying motivation. Section 3 continues this discussion by delving deeper into the game design, followed by a view into the implementational issues in Sect. 4 . In Sect. 5, we present topics related to marketing the applications. We give a broader discussion in Sect. 6, and the concluding remarks appear in Sect. 7 .

\section{Three Applications}

The games we have developed are not shoot-em-ups but focus on shooting as an activity with its nuances and specialities. The point of view throughout the entire development work has been sport, in an environment that is as realistic as possible. Naturally, such apps cannot be created without a thorough knowledge of the sport in question.

Kurt Thune Training was the first step to the world of shooting sport game apps. The game idea behind Pete Patruuna was similar, but it was intended for the young members of the Finnish Shooting Sport Federation. Biathlon X5 combines both shooting and skiing bringing more factors such as pulse and breathing rate into focus.

\subsection{Kurt Thune Training}

Kurt Thune Training is a smartphone application for Android, iOS and Windows Phone aimed directly at those who have target shooting as a hobby (see Fig. 1). The application simulates realistic rifle shooting event and enables the players to practice many areas of sport shooting outside of the real-world shooting range to improve their shooting scores. The game models the sight movements of a rifle shooter as realistically as possible, which allows the players to practice coordination between the eye and finger, right timing, right aiming picture, triggering, follow through, concentration, ability to "take" top results, and make sight adjustments.

\subsection{Pete Patruuna}

Pete Patruuna (see Fig. 2) is a smartphone application for Android, iOS and Windows Phone platforms intended for under 14 year-old members of the Finnish Shooting Sport Federation. The application allows the player to practice air rifle 

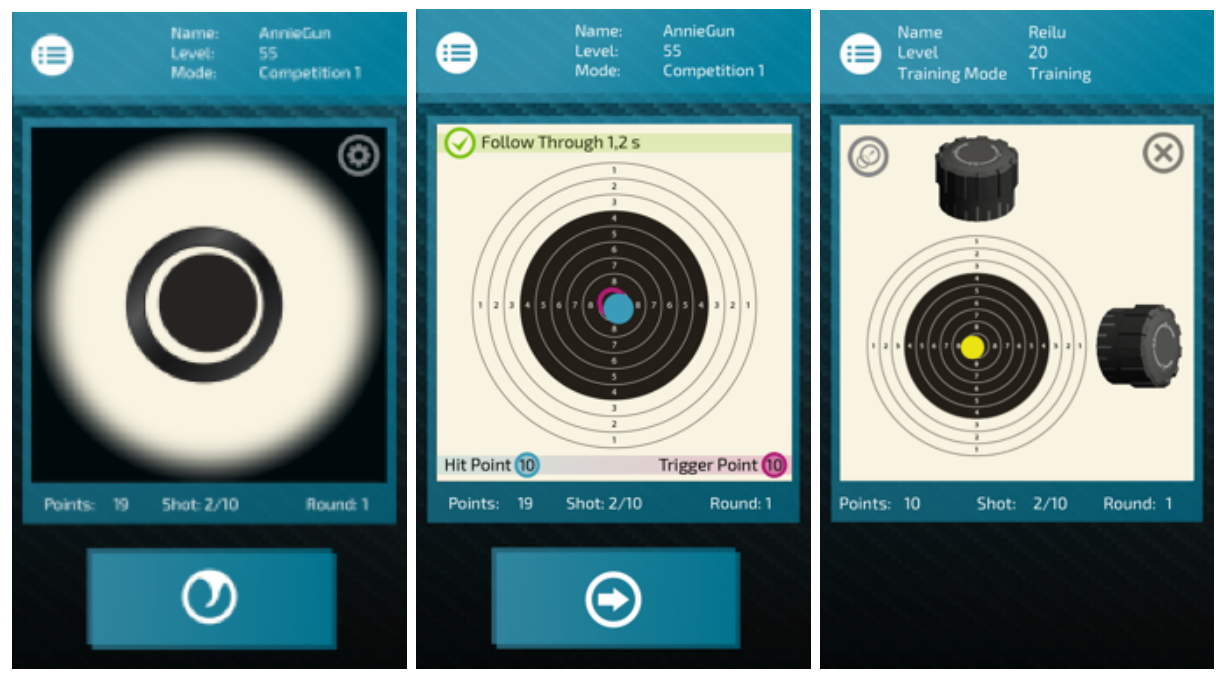

Fig. 1. Screenshots from Kurt Thune Training.

shooting by practicing right timing and aiming as well as adjusting the sights in a realistic manner. The players can also take part in a competition and compare their scores with other players' scores.

The aim of the application is to acquaint young players with shooting sports to attract new enthusiasts to the sport. The original vision behind the game was that a young person, who is an avid gamer, might get excited about the sport through the mobile game so much that they will start practicing the sport for real.

\subsection{Biathlon X5}

Biathlon X5 is an application made for three platforms: Android, iOS and Windows Phone (see Fig. 3). The goal of the application is to add value to the experience of watching a biathlon competition on TV and to encourage typical smartphone users to try the application and show them the phenomenon of biathlon. In Biathlon X5, the focus is on an entertainment, supplementary mobile service that is offered in addition to the TV screen. The interactive content of this service aims at producing additional information for the user and enhances the viewing experience with the use of a game.

The application allows the player to participate in a real-world competition in Kontiolahti, which hosted the IBU (International Biathlon Union) World Championships in March 2015, and compete with other players from around the world. The latter mode is called "Play Live" and it can be played only when a real-world competition is in progress. After each competition, the player can see the current position in the world ranking. There is also possibility to practice in the Kontiolahti track in "Play Now" mode. We have also implemented an in-app 

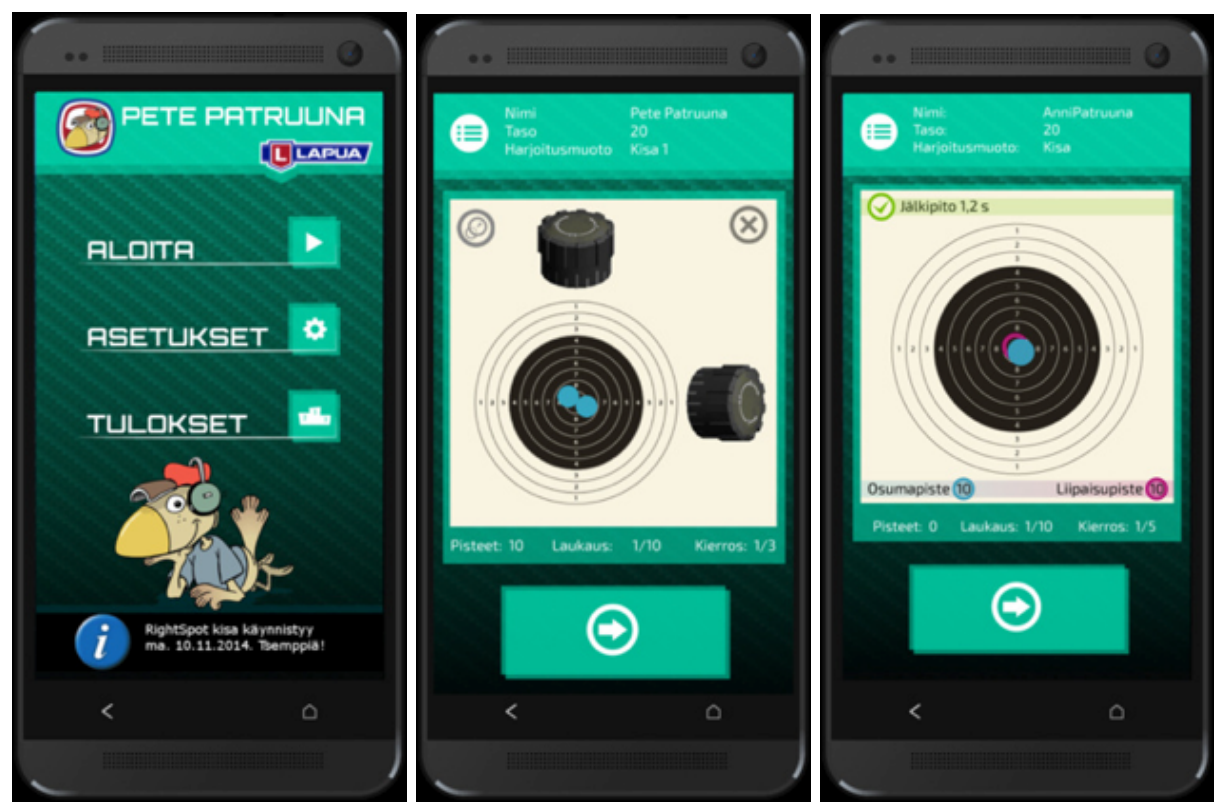

Fig. 2. Screenshots from Pete Patruuna.

purchase system to allow the players to buy different items that will make the gaming experience better.

The gameplay is a combination of simulation and management. In the first part, the player needs to manipulate the speed of skiing by moving sliders, and based on that the game system calculates the player's heartbeat, energy level and position. In the second part, the player enters a 3D simulation of a shooting stage on a biathlon track. Here, the most important things are reflexes, wind, and accuracy. As in the real-world biathlon, the end-result is a combination of skiing time, shooting time, and possible time penalties from missed targets.

\section{Game Design}

Sport games create a special challenge for game designers, because many people have high expectations about what the game will be like [1, pp. 74-75]. Sport games - unlike many other games - simulate a world the player knows about by watching or playing the sport in question. The player is not physically engaging in the sport but rather playing a game embodying the spirit, atmosphere and attitude of the activity.

In this section, we focus mainly on the design of Biathlon X5 as it is the most complicated of the three applications. Moreover, it includes and is built upon the work done in Kurt Thune Training and Pete Patruuna. Throughout the process the design of Biathlon X5 has been discovered by following the directions of these vectors: 

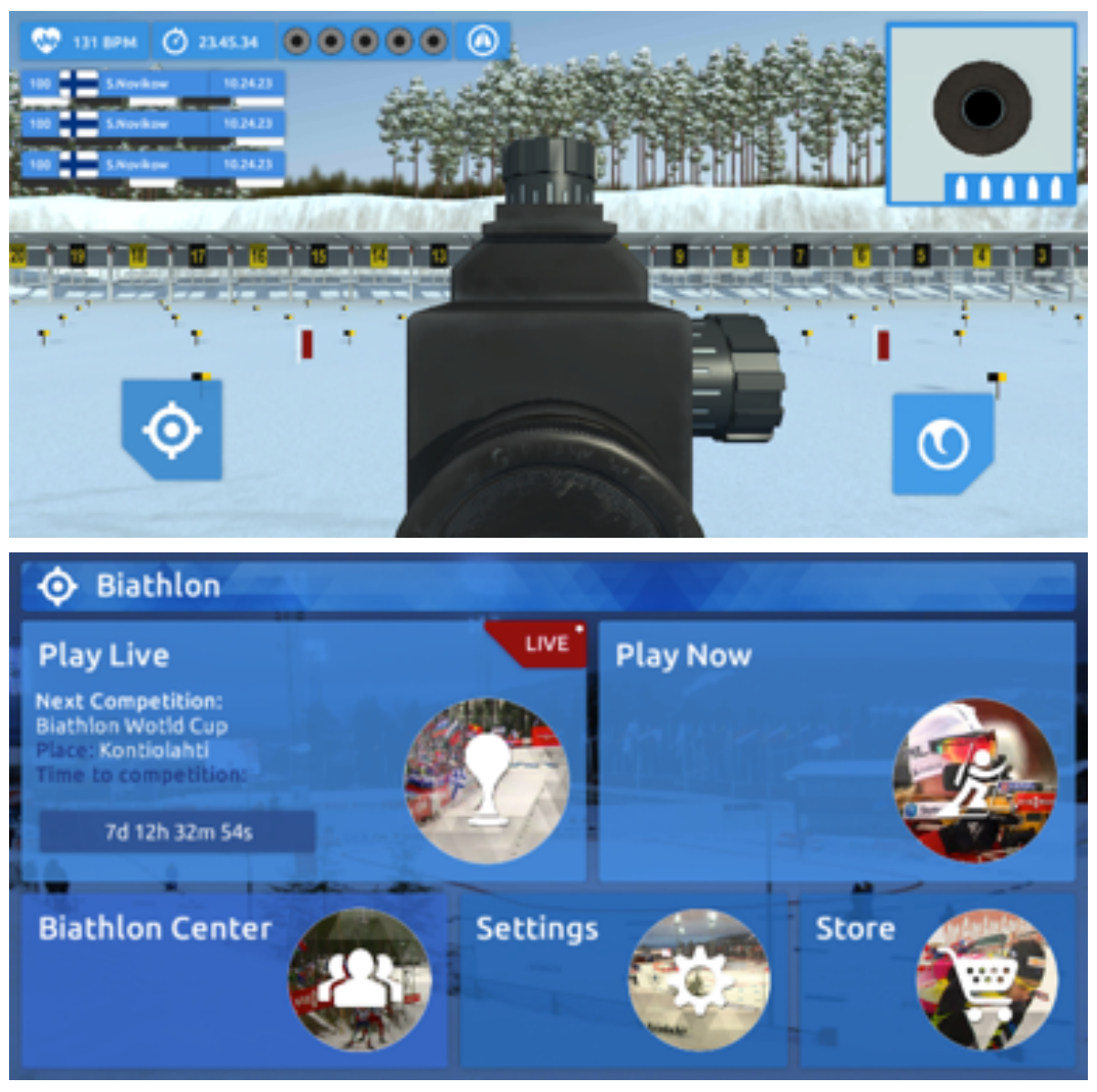

Fig. 3. Screenshots from Biathlon X5.

1. Fidelity and realism of the simulation: All the facts should be as correct as possible and the player should receive an experience of a real biathlon competition.

2. Agency and usability: The player should be immersed in the sport event.

3. Social media and second screen functionality: The player should be linked to the same experience with the other players as well as to the actual sports event.

4. Monetization: The game should produce revenue without hindering the overall playability.

These vectors are related to Murray's concept of the proper application of the affordances of the digital medium: spatiality, participation, procedurality, and encyclopedia [11, pp. 87-96]. Murray points out that for a designer it is not important to maximise the application of the affordances, and similarly here 
it has not been important for us to maximise the forces of these vectors (see Fig. 4). Instead, for example, in Biathlon X5, monetization has been important, but not in the excess. We did not want purchases being present everywhere in the application, unlike the feeling of realism, which was seen as the main goal of the project. We achieved medium level agency in the game and the social media/second screen vector played a relatively small part in the final outcome.

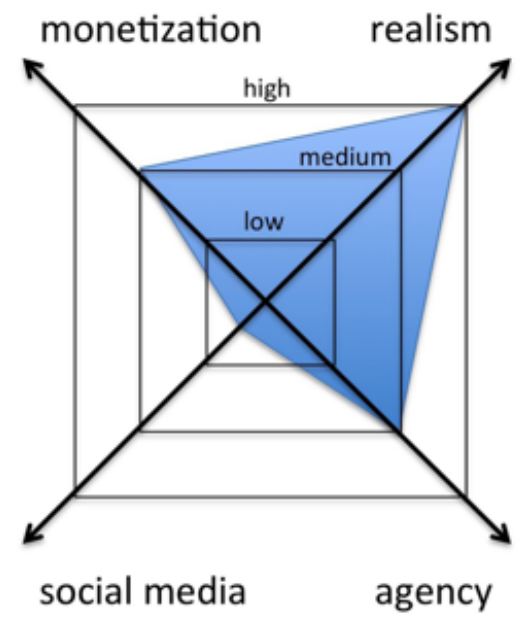

Fig. 4. The forces of the four vectors in Biathlon X5.

Whereas in Biathlon X5 we were tackling all these vectors, the first two applications focused mainly on vector 1 and, to a lesser extent, vector 4 . All these vectors have been used in the ideology of agile methods: We did not initially fix which features will be implemented in the final product, but the vectors served as ideals to aim at. At each point, when one path along any of the vectors appeared accessible, it was followed. This way we managed to come up, in time, with a product that is a complete and enjoyable game for the players, within a short development time.

Obviously, vector 1 dominated the overall design process, but it turned out to be problematic, because having the facts of the simulation and receiving a real biathlon experience contradict one another within the realm of a digital game. To give a player an experience of attending a biathlon competition means that we have to tell the player a story, where excitement is provoked by game mechanics and phenomena, such as exhaustion, are presented by game elements that serve better the production of game experience than simulation of realism.

From this perspective, biathlon, as a sport, posed an old game design conundrum: how to make a real-world endurance sport into a playable game. Most of the time in a real-world biathlon event is spent on the skiing track, which, 


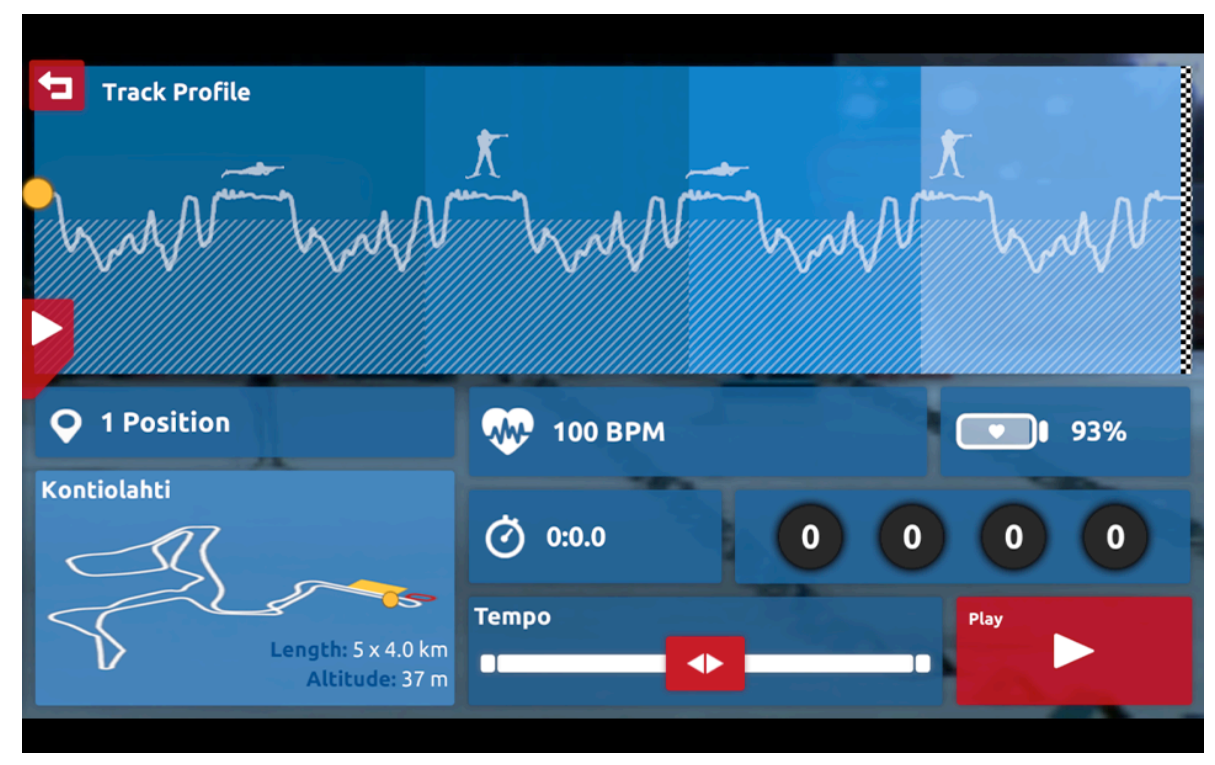

Fig. 5. Controlling the skiing.

game-wise, is not as interesting to play as shooting. For the audience, especially at home, this is a good time for social interaction. The television commentators make use of this time by analysing the athletes and relating other kinds of background information. We saw this kind of time valuable and did not want the skiing part of the game to require intensive attention-especially because vector 3 was pulling the design to another direction. Therefore, we decided to have the players to input a few parameters for the skiing (see Fig. 5). The players have only one input, tempo, that they can control during skiing. The tempo can be set for different sections of the track or it can be changed whenever the player chooses to pay attention to the game. The critical outputs that the player should observe are heartbeat rate (BPM) and the energy level (in percents).

We considered social media and involvement in the actual event an important factor, and vector 3 counted much in the initial design efforts. The original concept aimed at that the game does not disturb watching the actual live competition. Following the competition is typically a social event that the game should not hinder that significantly. Moreover, the game should improve the experience of following the live event. It can increase the social aspects, for example, by allowing the spectators to compete against one another. The game aims also at increasing the interest in biathlon and biathlon events.

Despite the initial interest, vector 3 was not followed so much later on, partly because of a tight schedule and partly because of the bad ratio of risks versus benefits. Social media is still very fresh realm and it has been discovered with 
serious risks of abuse. Also, it turned to be difficult to incorporate the idea of a second screen into the design, because it means that the game would be secondary to the actual live broadcast from the sport event. Games, being an interactive media by nature, are not ideal content for the second screen.

Our experiences confirm that game monetization design, vector 4, should have been included more already early on. Now, it dominated the final stages of the design process, which made it hard to include, for example, in-app purchases into the game events.

\section{Implementation}

All the three applications were implemented using Unity game engine [18]. During the development we encountered four implementational issues that we will address in detail here.

\subsection{Database}

One of the functionalities implemented in the Biathlon X5 was the ability to compete against other users. For this reason, we created a special highscore system. In Kurt Thune Training and Pete Patruuna we used a simplified solution, but now we had to extend the multiplayer functionalities. The system is responsible for storing data on the server, retrieving it and creating new competitions. Although the idea was simple, resolving the real-time skiing of other players' overview turn out to be challenging. Therefore, the saved information is used in two ways: (1) just to display the best result of a player and, based on the score, place the players in the ranking list, and (2) to store the checkpoint times, to re-create and simulate back the skiing on the diagram. Based on that, the player can follow the other contestants like during a real-world competition. We also took security matters into account, when designing and implementing the system.

The database consists of three tables: users, race events, and high scores for all competition events. When a player starts the application, a new user is created in the database. When the player launches the competition, the application retrieves the 50 best players relevant to the selected event. After the player has finished the competition, the data is uploaded to the server. The data consists of four entries in the form of

- the checkpoint times,

- the number of misses on each shooting,

- the final time, and

- the total number of misses.

The entries are stored in JSON format. On the server side, the score is checked, and only the better score gets updated in the database table. Before accessing the server, the request needs to pass a security control, which uses a public key encryption system. 


\subsection{User interface}

Implementing a multiplatform user interface (UI) is always a challenging task. Especially in mobile platforms different aspect ratios, resolutions and support to old devices that have a low amount of memory available makes the UI development a slow process. In some cases, we might need two sets of UI graphics, one for low and one for high resolution devices to lower the memory footprint. For different resolutions and aspect ratios, there are different ways to achieve clear and functioning UI. One way is to focus on creating UI that can scale up or down based on different screen sizes; the other way is to make pixel-perfect UIs for each specific device or size.

The performance of the application also poses challenges. It is best to decide at the very beginning the lowest supported device for each platform that project will be released on. Moreover, the development team should always have at least one device for each platform for testing purposes during the development cycle, but, preferably, the set of test devices should cover different makers and models. Sometimes even that is not enough, but there might be variance in the same device and model from within.

\subsection{Advertisements and in-app purchases}

All the three applications contain advertisements. Our system allows to create an own set of ads and place them in any place in the application, for example, on UI elements or blend into 3D objects. Kurt Thune Training and Pete Patruuna use a custom made advertising system for displaying banner ads inside menus. The system uses a web server where data and pictures is fetched to be displayed on predefined locations inside the app. Administrator can also define website addresses for specific ads.

For Biathlon X5, this system was extended to create and place ads also to 3 D objects. In addition, Biathlon X5 can also show Google AdMob banner and interstitial ads in menus and scene changes. AdMob was selected because it works on all mobile platforms with one plugin. To increase income we implemented an in-app system using OpenIAB plugin to help cross-platform developing. This plugin allowed a faster implementation of desired in-app purchases but required still quite much platform specific work. The implemented system allows a player to purchase new skins for the rifle or to purchase a head start that will open upcoming live competition before it becomes available to all.

\subsection{Deployment}

Deployment to multiple platforms even on Unity requires much work. Most problematic areas are the Unity plugins and requirements for different mobile stores. The biggest difficulties we encountered were when using plugins, which often work differently on different platforms - or they can even be totally unsupported. With Biathlon X5, we had particular problems with the JSON plugin on Windows Phone. Because some libraries are not supported by that platform, we had to modify the plugin to meet our requirements. 


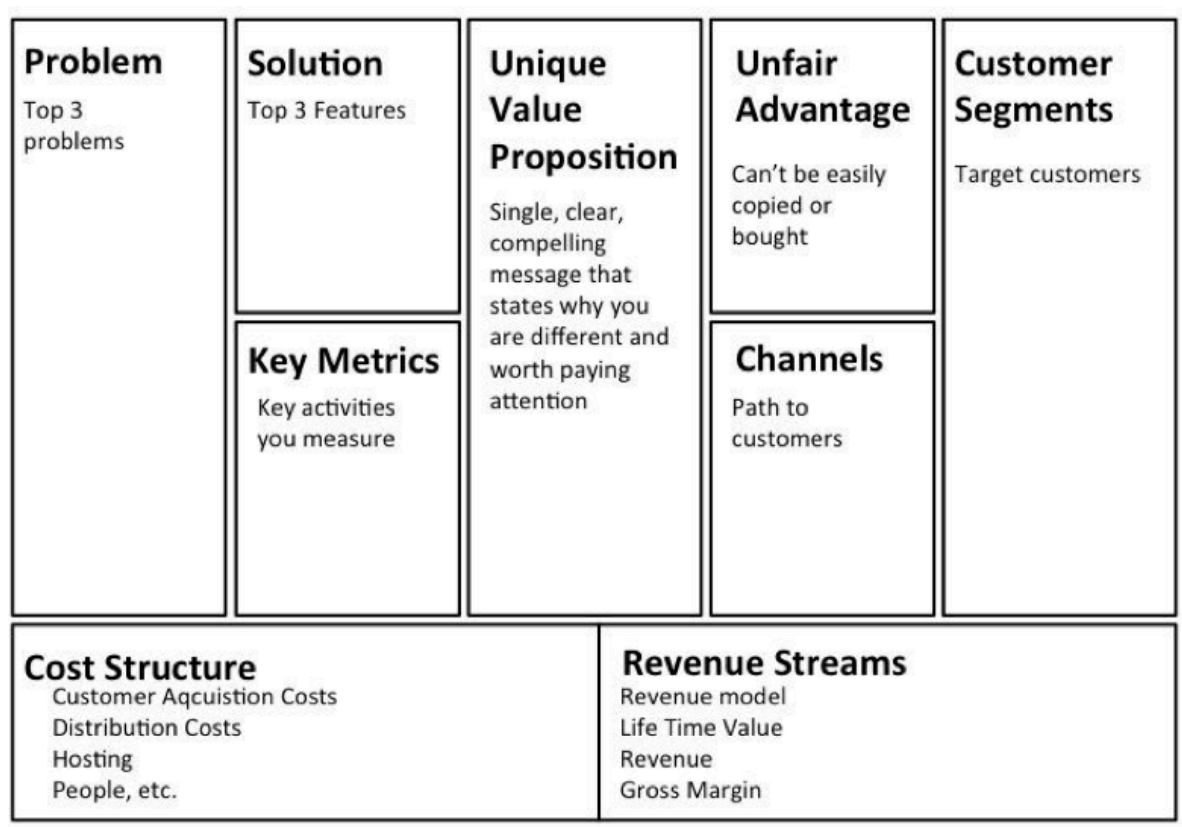

Fig. 6. Lean canvas [15].

Last thing to remember are the requirements for different mobile application stores. The fastest release is possible on Android and Windows Phone, since it takes only few hours from the moment the application is uploaded. Recently, Google Play announced that it is introducing a human review process that might slow down the review time [8]. In comparison, the review of an iOS app can take about seven days after which the app will be ready to release - provided that it has passed the review. Therefore, it is best not to leave the release process for the last moment. Certain requirements can slow down the release process (especially on iOS platform). It is also good to do test release on smaller markets similar to the main target. For example, in our case we have used Finland for test releases before releasing the applications worldwide.

\section{Marketing}

This section presents the path leading to the current business model. The story captures the main elements of Lean Canvas tool, an adaption of traditional business model canvas of Osterwalder et al. [13] created by Ash Maurya (see Fig. 6).

Following that approach the starting point for business model design is the identification of problems that the business idea tries to solve. This problem 
identification is naturally strongly linked with the right customer segments. As mentioned earlier, the second screen feature was left out of this application. Still, market is two-sided, since the players of the game are not only customers but also audience to advertisers. Also, for the future development International Biathlon Union (IBU) as well as single event organizers may be customers. Therefore, the problems are here presented, not only from the end user perspective, but also from the perspective of the biathlon as a sport.

Starting from the end user, the very nature of biathlon - shooting - makes it rather difficult hobby for ordinary people. Legal regulation of shooting generates remarkable barriers to start that hobby. Therefore, most of the biathlon race followers lack own experience of the sport, which makes it harder to understand race situation, strategies, etc. That is, TV experience of the race could be deeper and more exciting. The lack of own experience makes commitment to the sport easily thinner than, for instance, in soccer, ice hockey or any other sport where the followers also have their own experience in playing those games.

Another problem for biathlon is the demographics of the followers. The viability of a sport is based on popularity and attractiveness to advertisers. Basically, the current situation is rather good, since biathlon is very popular sport in Central-Europe and in Russia. For instance, during the world cup season 20122013, there were 140 million TV-spectators for the most popular race. There is, however, one problem: the demographics. Most of the spectators are over 60 years old and more than half are retired. In the case of biathlon the fundamental problem, generally speaking, is to generate new followers to the sport.

In order to produce a viable service, it is critical to identify special needs for each of the segments. Within the consumer segment we can identify three rough sub segments: fans of biathlon, generic winter sports spectators and random spectators. Since there are advertisers, it is obvious that we have a two-sided market at hand. Following the logic of a two-sided market, the customers in the latter group are both biathlon race organizers (IBU, local teams) and broadcasters. Based on the previous, the value proposition for the end users is an experience very close to the real biathlon one. For the biathlon race organizers and other right holders, the value proposition is better content for the end-user and new, more committed fan-base.

The second screen case - or service for biathlon race organizers - present a typical egg-chicken problem of network markets is present. To make the firm side interested, a solid customer base is needed. In the current competitive environment it is not easy to gather critical user mass for a novel application. These factors make it difficult to sell new services to content producers. Even if there is need and will to develop more participatory services to improve user experience, the B2B-customers often choose safer solution. In this case general solution, as good biathlon simulation game as possible, is a good starting point. With a superior solution, it is possible to build up big enough end-user base also to be lucrative for business side of the two-side market.

A key factor driving the business growth is the channels delivering the product to the customers. The game is available for the customers in chosen appli- 
cation stores (App Store, Google Play, Windows Phone Store). In addition to delivery, the stores provide product information for the customers. The main challenge for new applications is the number of applications: in each store there are vast number of different applications competing not only for the customer attention but also for their most limited resource: time. This problem has been tried to cope with media presence: the developers of the idea has presented the game in TV and other media to make the game known to the users.

The last part of the model is the analysis of the sustainability of the competitive advantage. In this case, the original developers of the idea have a great biathlon sport know-how to reach all the relevant stakeholders and to deliver a full-scale authenticity to the players. Also, there is a dedicated multitalented team to carry out the development as well as networking capabilities to reach important interest groups and media visibility

\section{Discussion}

Recently, one of the objectives has been to serve new interesting content for biathlon fans and tourists visiting in biathlon events. For example, Hawking et al. [5] report that tourism service has special needs (e.g., do-it-yourself travelling) that requires tailor-made applications. These applications should offer for the users services which are relaxing and enjoyable. In addition, services should be narrative to enrich travelling experiences. Mobile devices users have currently a need for ambient intelligence, for user friendly UIs, and for services just in time (location-aware and/or context-aware).

Regarding the future, researchers have investigated intensively for years how mobile devices could be utilized in tourism. For example, Nielsen et al. [12] have categorized user experiences in four areas, namely activating, learning, entertaining, and experiencing. Especially Biathlon X5 can provide new possibilities for sport event organizations to fulfill the users' needs in these four areas. As Pine and Gilmore [14] have stated, user experience requires a lot of financial resources. In order to increase the customer's interest we have to refine the raw materials (in this case all the content visible in the television plus all the marketing material) to new products (such as applications presented in this paper), and to new services (which are offering new user experiences in all four categories listed above).

The Biathlon X5 project has been tested in real-life conditions in Kontiolahti IBU World Championships in March 2015. All in all, one of the advantages in this project has been to focus not only in piloting or demonstrating something new and innovative but also on commercialization. Collected feedback from the field in the world championships has been mainly promising. This first version contained content just dedicated to the Kontiolahti venue. In the future, we need more content including tracks, avatars, and shops. We believe that this kind of a hybrid game application (containing management and real-time playing) has business potential but needs a lot of more research. It will be interesting to study how players will use these type of games in a long-term period (e.g., 
covering a whole biathlon season). One of the future directions can be to focus also on new marketing innovations. In fact, Biathlon X5 can be seen as an ecosystem which consists of various applications or screens which can be used simultaneously. For example, real-time playing sport fans might like to play in public environments. This could include testing players' physical and shooting conditions. Motion detection, wearable computing, and intelligent environments could give us a lot of new possibilities providing new added-value services as a part of this ecosystem. Naturally, these features of the game requires extensive usability evaluations.

One approach to develop that kind of an innovative product is to do it in collaboration with university partners like the Turku Game Lab, whose research philosophy is in applied research. This project is a typical example in which we will try to apply the latest game technologies in industrial cases. Research and development is implemented in various test generate cycles which has similarities to the IS research framework presented by Hevner et al. [7]. That is to say, we are designing artifacts, analysing problem relevancy, late evaluating research contributions typically based on usability evaluations based rigorous research methods. These test generate cycles in our case can be seen in two different stages. In the case of Rightspot, we are doing research and development which is based on agile methods. Based on improvements and alternative solutions we will get a progress which is in line with the customer's directions. Test generate cycles can be seen also in a more general perspective. We are namely testing game technologies in various cases parallel. This will open us a better understanding how these up-to-date technologies can be applied in various fields such as tourism and sport but also, for example, edutainment, healthcare and technology industry. Interacting in the same time with various clients and testing pilots, prototypes, demonstrations, and even products in various domains will improve our understanding of the potential of game technologies in new service innovation development.

\section{Conclusion}

Shooting sports provide an interesting area for mobile applications. Although one can label it as a niche market, it does have potential to be interesting even for an average player. In this paper, we presented three applications that aim at fulfilling this potential. We analysed the development process from various perspectives - design, implementation, and marketing - and proposed new ways for utilizing them.

\section{Acknowledgments}

Our warmest thanks go to Max Lindblad and Hanna Ahtosalo who acted as a lead programmer and a lead artist, respectively, in Kurt Thune Training and Pete Patruuna, and to Jonathan Sarry who worked on the database for Biathlon $X 5$. We would also like to thank Tapani Liukkonen for his input on the historical game review. 


\section{References}

1. Adams, E.: Fundamentals of Game Design. New Riders, San Francisco, CA, USA, third edn. (2014)

2. Epyx: Summer Games. Software (1984)

3. Epyx: Winter Games. Software (1984)

4. Harlequin: International Sports Challenge. Software (1992)

5. Hawking, P., Stein, A., Sharma, P., Nugent, D.: Emerging issues in location based tourism systems. In: Proceedings of the International Conference on Mobile Business. pp. 75-81 (2005)

6. Herman, L.: Phoenix: The Fall \& Rise of Videogames. Rolenta Press, Springfield, NJ, USA (2001)

7. Hevner, A.R., March, S.T., Park, J., Ram, S.: Design science in information systems research. MIS Quarterly 28(1), 75-105 (2004)

8. Kim, E.: Creating better user experiences on Google Play. Android Developer Blog, March 17 (2015), http://android-developers.blogspot.com/2015/03/ creating-better-user-experiences-on.html

9. Konami: Hyper Sports. Software (1984)

10. Kuju Entertainment: Microsoft Train Simulator. Software (2001)

11. Murray, J.H.: Inventing the Medium: Principles of Interaction Design as a Cultural Practice. MIT Press, Cambridge, MA, USA (2012)

12. Nielsen, L.B.: Post Disney experience paradigm?: Some implications for the development of content to mobile tourist services. In: Proceedings of the 6th International Conference on Electronic Commerce. pp. 657-666 (2004)

13. Osterwalder, A., Pigneur, Y.: Business Model Generation: A Handbook for Visionaries, Game Changers, and Challengers. John Wiley \& Sons, Hoboken, NJ, USA (2010)

14. Pine, J., Gilmore, J.: The Experience Economy. Harvard Business School Press, Boston, MA, USA (1999)

15. Spark59, Inc.: How to create your lean canvas, https://leanstack.com/LeanCanvas.pdf, accessed April 22, 2015

16. subLOGIC: Microsoft Flight Simulator. Software (1982)

17. Tynesoft Computer Software: Winter Olympiad 88. Software (1988)

18. Unity Technologies: Unity. Webpage (2015), http://unity3d.com/

19. U.S. Gold: Winter Olympics: Lillehammer '94. Software (1993) 